\title{
Femur başı avasküler nekrozunda hiperbarik oksijen tedavisi
}

\section{Hyperbaric oxygen therapy as a treatment for avascular necrosis of the femoral head}

\author{
Cem Coşkun $\mathrm{Avcl}^{1}$, Mehmet Kürşat Yılmaz', Deniz Gülabi ${ }^{2}$ \\ ${ }^{1}$ İstanbul Medipol Üniversitesi Tıp Fakültesi, Ortopedi ve Travmatoloji Anabilim Dalı, İstanbul \\ ${ }^{2}$ Istanbul Kanuni Sultan Süleyman Eğitim ve Araştırma Hastanesi, Ortopedi ve Travmatoloji Kliniği, İstanbul
}

\begin{abstract}
Avasküler nekroz, trabeküler kemik ve kemik iliğinin ölümüdür ve en sık femur başında görülür. Patogenezin intraosseöz mikrosirkülasyon bozulması ile ortaya çıkan iskemiden kaynaklandığına inanılmaktadır. Tedavideki amaç femur başındaki çökmeyi engellemek ve böylece osteoartrit gelişimini durdurmaktır. Hiperbarik oksijen tedavisi, femur başı avasküler nekrozunun altta yatan patofizyolojisini düzeltmeyi hedefleyerek etki eder. Bu tedavi tüm vücuda atmosfer basıncından daha yüksek basınçlarda \%100 oksijen verilmesini içerir. Hiperbarik oksijen tedavisi, arteriyollerde vazokonstrüksiyon yaparak enflamasyonun azalmasına, kollajen ve kan damarı sentezinin teşvik edilmesine (anjiyogenez) yol açar. Trabeküler kemikte nekrotik bölgenin ekstrasellüler sıvı yoluyla direkt olarak oksijenlenmesini de sağlar. Tüm bunlar sonucu femur başında venöz basınç düşer ve mikro dolaşım düzelir. Böylece klinik olarak ağrı önemli ölçüde azalır, eklem hareketlerinde artış sağlanır. Hiperbarik oksijen tedavisi, avasküler nekroz tanısı konmuş hastalarda erken dönemde (evre I-II) yalnızca gözlem yerine tek başına veya diğer tedavilerle beraber (kokteyl tedavi) uygulanabilir.
\end{abstract}

Anahtar sözcükler: avasküler nekroz; osteonekroz; hiperbarik oksijen tedavisi; konservatif tedavi

\begin{abstract}
Avascular necrosis is the death of trabecular bone and bone marrow and is most common in the femoral head. The pathogenesis is believed to result from ischemia caused by intraosseous microcirculation impairment. The aim of the treatment is to prevent the collapse of the femoral head and thus to stop the development of osteoarthritis. Hyperbaric oxygen therapy acts by aiming to correct the underlying pathophysiology of avascular necrosis of the femoral head. This treatment involves supplying $100 \%$ oxygen to the whole body at pressures higher than atmospheric pressure. Hyperbaric oxygen therapy causes vasoconstriction in the arterioles, reducing inflammation and promoting collagen and blood vessel synthesis (angiogenesis). It also provides direct oxygenation of the necrotic region in the trabecular bone via the extracellular fluid. As a result of all these, venous pressure decreases in the femoral head and microcirculation improves. Thus clinically, pain is significantly reduced and joint movements are increased. Hyperbaric oxygen therapy can be applied in patients diagnosed with avascular necrosis in the early period (stage I-II) alone or together with other treatments (cocktail therapy) instead of only observation.
\end{abstract}

Key words: avascular necrosis; osteonecrosis; hyperbaric oxygen therapy; conservative therapy

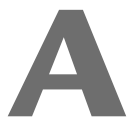

vasküler nekroz (AVN) trabeküler kemik ve kemik iliğinin ölümüdür ve en sık femur başında görülür. ${ }^{[1]}$ Patogenezin intraosseöz mikrosirkülasyon bozulması ile ortaya çıkan iskemiden kaynaklandığına inanılmaktadır. Hastalık en sık genç erişkinlerde ortaya çıkar ve ortalama yaş 38'dir. ${ }^{[2]}$ Prognoz değişkendir.

Tedavideki amaç femur başındaki iskeminin azaltılması, subkondral kemikteki çökmenin engellenmesi ve böylece son evre osteoartrit gelişiminin durdurulmasıdır. ${ }^{[3]}$ Femur başı avasküler nekrozu (FBAVN) hastaları, primer osteoartritli hastalara göre daha genç ve daha aktif hastalar olduğundan bu hastalarda erken osteoartrit gelişimin önlenmesi büyük önem taşımaktadır. Bilindiği gibi avasküler nekroz tedavisi için yapılan total kalça artroplastisinin sonuçları ve sağkalımı primer osteoartrite göre daha az başarılıdır. Erken tanı ve uygun tedavi ile artroplasti riski azaltılabilir ve iyi sonuçlar elde edilebilir. ${ }^{4]}$ Bu amaçla cerrahi ve konservatif tedaviler uygulanabilir. Konservatif tedavi yöntemleri daha çok hastalığın erken evrelerinde kullanılmaktadır. Konservatif tedavi farmakolojik ajanlar ve biyofiziksel tedavilerden oluşur. Hiperbarik oksijen (HBO)

- İletişim adresi: Doç. Dr. Cem Coşkun Avcı, İstanbul Medipol Üniversitesi Tıp Fakültesi, Ortopedi ve Travmatoloji Anabilim Dalı; Göztepe, Metin Sk. No:4, 34214 Bağcılar, İstanbul Tel: 0532 - 3661295 e-posta: ccemavci@gmail.com

- Geliș tarihi: 17 Eylül 2020 Kabul tarihi: 6 Ekim 2020 


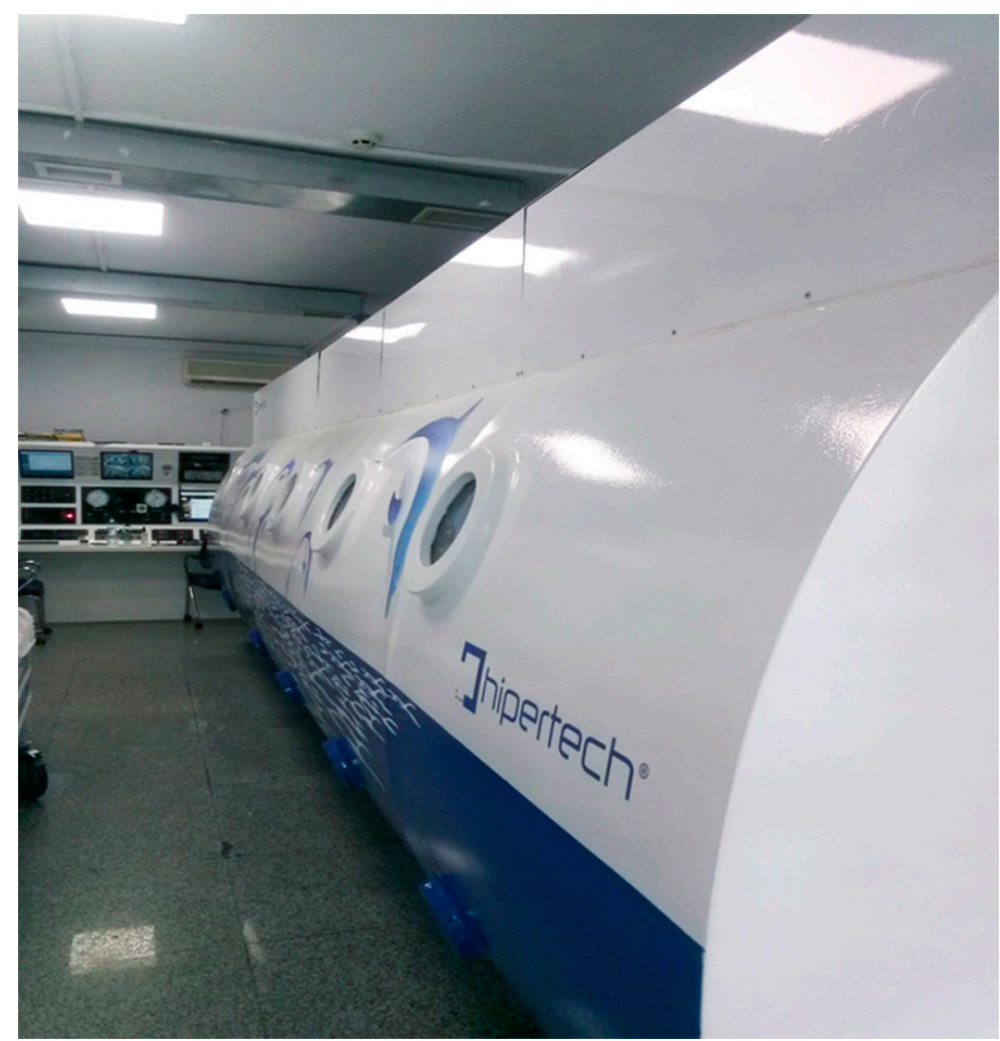

Şekil 1. Hiperbarik oksijen tedavi kabini.

tedavisi, ESWT (Extracorporeal Shock Wave Treatment) ve elektromanyetik tedaviler ile birlikte biyofiziksel tedavi seçeneklerinden biridir. FBAVN'nin farmakolojik tedavisinde statinler, vazodilatörler, bisfosfonatlar ve antikoagülanlar kullanılmaktadır. ${ }^{[3,4]}$

HBO tedavisi 2-2,5 ATM basıncındaki \%100 oksijenin, özel basınçlı kabinlerde hastaya belirli süre ve dönemlerle inhale ettirilmesiyle uygulanır (Şekil 1). $\mathrm{Bu}$ tedavi sonucu plazma oksijen düzeyi binde 32 düzeyinden, \%5 düzeylerine kadar yükselir. AVN'de femur başındaki nekrotik bölgeye iskemi nedeniyle hemoglobin aracılığıyla oksijen taşınması bozulmuştur. Tedavi sonucu plazmada yükselen çözünmüş̧ oksijen iskemik hücrelerin ekstrasellüler sıvıdan direkt olarak oksijenlenmesini sağlar. ${ }^{[3,5]}$ Çevre oksjien basıncındaki bu artış, oksijenin derin dokulara yayılabileceği anlamına gelir, bu nedenle oksijen, düşük kan akışı ile bile iskemik dokulara ulaşır. ${ }^{[6]}$ Ayrıca yüksek düzeydeki oksijen arteriollerde vazokonstrüksiyona neden olarak venöz basıncın düşmesini sağlar; lokal hipoksi ve enflamasyon azalır, kemik iliği ödemi geriler. Lökosit aktivitesinin artmasıyla beraber kollajen sentezi ve kan damarı büyümesi de artar. $^{[7]}$ Böylelikle hem anjiyogenezis yoluyla oluşan yeni damarlar hem de mikrosirkülasyondaki olumlu etkiler, trabeküler dolaşımın yeniden düzenlenmesini sağlar. ${ }^{[8]}$ Dolaşımdaki bu olumlu değişiklikler kemik iliği ödemini azaltarak hastanın ağrı düzeyinde anlamlı düşüşlere neden olur. Ağrının azalması ile eklem hareketleri rahatlar ve hastanın fonksiyonel kapasitesinde önemli oranda artış sağlanır. Erken dönemdeki olumlu etkinin ana mekanizması budur. Sonuçta; kemik içi basıncı azalmış, daha iyi perfüze olan ve oksijen konsantrasyonu yüksek kemik dokusu sağlanmış olur.

HBO tedavisinin tüm bu olumlu etkilerinin yanı sıra muhtemel olumsuz etkileri de vardır. Yüksek düzeydeki oksijenlenme sekonder olarak osteoklastik aktiviteyi artırmaktadır. Bu durum subkondral kemikteki çökmeyi ve böylece evre II'den III'e geçişi hızlandıran olumsuz bir etkidir. ${ }^{[9,10]}$ Ayrıca HBO tedavisindeki yüksek maliyet de göz önünde bulundurulması gereken bir faktördür (Şekil 2).

HBO tedavisinin sonuçlarına yönelik olarak literatürde kanıta dayalı bilgi kısıtıdır. Çalışmaların 


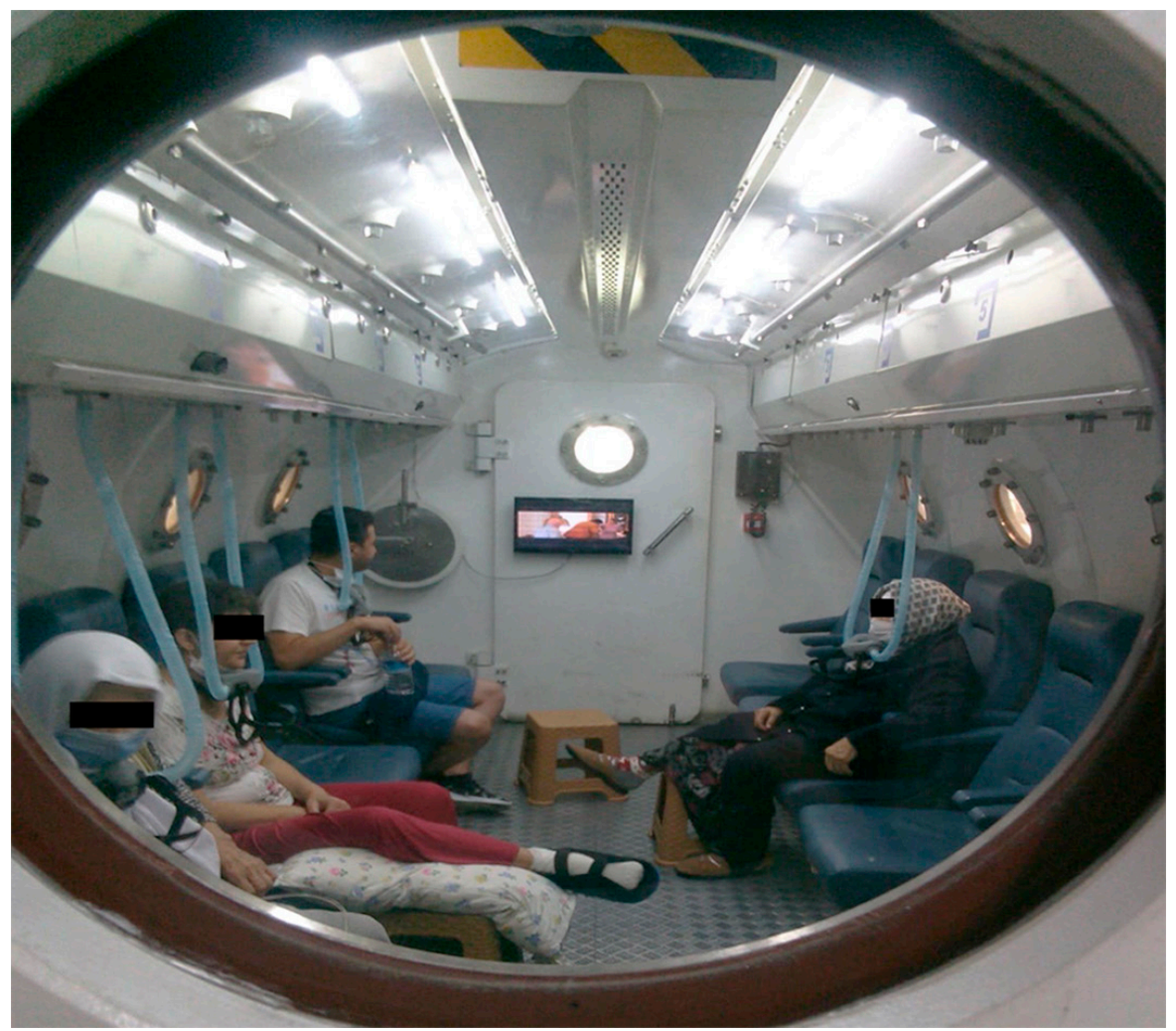

Şekil 2. Hiperbarik oksijen tedavisi.

hemen hepsi küçük olgu serileri veya olgu-kontrol serilerinden oluşmaktadır. Serilerin çoğunda da HBO tedavisi tek başına uygulanmamış, diğer tedavilerle birlikte kokteyl tedavi olarak uygulanmış olduğundan elde edilen sonuçların değerlendirilmesi ve çıkarım yapılması zorlaşmaktadır. ${ }^{[11,12]}$ Yine bu çalışmaların hiçbirinde kontrol grubu da olmadığından bilimsel düzeyi tartışmalıdır. Ayrıca FBAVN'de sonuçlar etiyolojiyle yakından ilişkilidir, bu nedenle çalışmalarda homojen hasta grubu oluşturmak mümkün olmamaktadır. Tüm bu olumsuzluklara rağmen FBAVN tanısı konulan kişilerde yapılan klinik çalışmalar HBO tedavisinin hastalık prognozunu büyük ölçüde olumlu yönde etkilediğini ve invaziv cerrahi müdahaleleri geciktirdiğini göstermiştir. Örneğin, Camporesi ve ark. tarafından yapılan bir çalışmada Ficat sınıflamasına göre evre II AVN'li 20 hastaya 6 hafta boyunca 30 seans HBO tedavisi uygulanmış ve bu hastalar ileriye dönük bir çalışmayla 7 yıl boyunca takip edilmiştir. ${ }^{[12]}$ Hastaların hiçbirinde 7 yıl sonunda artroplasti uygulanmamış ve tamamının ağrısız bir kalça ile yaşamını sürdürdüğü gözlenmiştir.
Ayrıca yedi hastada radyolojik olarak tamamen iyileşme saptanmıştır. Reis ve ark. tarafından yapılan bir başka önemli çalışmada ${ }^{[3]}$ Steinberg evre I AVN'li 12 hasta değerlendirmeye alınmış ve 100 gün boyunca günlük $\mathrm{HBO}$ tedavisi uygulanmıştır. Hastaların \%81'inde hem klinik hem de radyolojik olarak normale dönüş saptanmıştır.

illeri deneysel ve klinik çalışmalar, tedavi deneyiminin artması ve tedavi planına HBO protokollerinin eklenmesi yeni araştırma fırsatları sağlayacaktır HBO tedavisi maliyeti yüksek bir tedavi şeklidir. Bu sonuçlar HBO tedavisinin erken evre FBAVN tedavisinde bir dereceye kadar etkinliğini gösterse de, tedavinin etkili dozunu belirlemek, HBO tedavisinin uzun vadeli maliyet-yarar etkilerini göstermek için iyi planlanmış ve çok merkezli çalışmalara ihtiyaç vardır.

Sonuç olarak, HBO tedavisi FBAVN'de genel kabul görmüş bir tedavi şekli olmamakla birlikte evre I-II tanısı konmuş hastalarda ağrıyı azaltıp kalça skorlarında belirgin bir artış sağlamaktadır. Bu nedenle erken dönemde yalnızca gözlem yerine uygulanabilir bir tedavi seçeneği olarak değerlendirilebilir. 


\section{KAYNAKLAR}

1. Mazières B. Osteonecrosis. In: Kippel JH, Dieppe PA. Rheumatology. Mosby-Year Book, London: 1994; p.41.1-41.8.

2. Güneş A, Aktaş Ş. A review of hyperbaric oxygen therapy for avascular necrosis. Acta Medica Mediterranea 2017;33(1):29-34. Crossref

3. Reis ND, Schwartz O, Militianu D, Ramon Y, Levin D, Norman D, Melamed Y, Shupak A, Goldsher D, Zinman C. Hyperbaric oxygen therapy as a treatment for stage-I avascular necrosis of the femoral head. J Bone Joint Surg Br 2003;85-b(3):3715. Crossref

4. Camporesi EM, Bosco G. Mechanisms of action of hyperbaric oxygen therapy. Undersea Hyperb Med 2014;41(3):247-52. https://pubmed.ncbi.nlm.nih.gov/24984320/

5. Marx RE, Ehler WJ, Tayapongsak P, Pierce LW. Relationship of oxygen dose to angiogenesis induction in irradiated tissue. Am J Surg 1990;160(5):519-24. Crossref

6. Thom SR. Oxidative stress is fundamental to hyperbaric oxygen therapy. J Appl Physiol 2009;106(3):988-95. Crossref
7. Nylander G, Lewis D, Nordstrom H, Larsson J. Reduction of postischemic edema with hyperbaric oxygen. Plastic Reconstr Surg 1985;76(4):596-601. Crossref

8. Huri G, Dündar K, İyetin Y, Doral MN. Erken evre femur başı avasküler nekrozlu olgularda hiberbarik oksijen tedavisi. Göztepe Tıp Derg 2011;26(3):108-11. Crossref

9. Hunt TK, Pai MP. The effect of varying ambient oxygen tensions on wound metabolism and collagen synthesis. Surg Gynecol Obstet 1972;135(4):561-7. https://pubmed.ncbi. nlm.nih.gov/5077722/

10. Hsu SL, Wang CJ, Lee MSS, Chan YS, Huang CC, Yang KD. Cocktail therapy for femoral head necrosis of the hip. Arch Orthop Trauma Surg 2010;130(1):23-9. Crossref

11. Scherer A, Engelbrecht $\mathrm{V}, \mathrm{B}$ Bernbeck, May P, Willers R, Göbel $U$, Mödder U. MRI evaluation of aseptic osteonecrosis in children over the course of hyperbaric oxygen therapy. RöFo 2000;172(10):798-801. Crossref

12. Camporesi EM, Vezzani G, Bosco G, Mangar D, Bernasek TL. Hyperbaric oxygen therapy in femoral head necrosis. J Arthroplasty 2010;25(6):118-23. Crossref 